\title{
GRUNDZÜGE
}

\author{
DER

\section{PHYSISCHEN ERDKUNDE} \\ VON \\ PROF. DR. ALEXANDER SUPAN, \\ HERAUSGEBER VON PETERMANNS GEOGRAPHISCHEN MITTEILUNGEN.
}

ZWEITE, UMGEARBEITETE UND VERBESSERTE AUFLAGE.

MIT 203 ABBILDUNGEN IM TEXT

UND ZWANZIG KARTEN IN FARBENDRUCK.

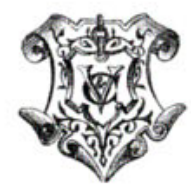

L E I P Z I G,

VERLAG VON VEIT \& COMP.

1896. 
Druck von Metzger \& Wittig in Leipzig. 